\title{
Promoting family meals: a review of existing interventions and opportunities for future research
}

This article was published in the following Dove Press journal:

Adolescent Health, Medicine and Therapeutics

22 June 2015

Number of times this article has been viewed

\section{Laura Dwyer' \\ April $\mathrm{Oh}^{2}$ \\ Heather Patrick ${ }^{1,3}$ \\ Erin Hennessy ${ }^{4}$}

'Health Behaviors Research Branch, Behavioral Research Program, Division of Cancer Control and Population Sciences, National Cancer Institute, Bethesda, MD, USA; ${ }^{2}$ Health Communication and Informatics Research Branch, Behavioral Research Program, Division of Cancer Control and Population Sciences, National Cancer Institute, Bethesda, MD, USA; ' ${ }^{2}$ ive Healthier, Bethesda, MD, USA; ${ }^{4}$ Clinical Research Directorate/ Clinical Monitoring Research Program, Leidos Biomedical Research, Inc., Frederick National Laboratory for Cancer Research, Frederick, MD, USA
Correspondence: Erin Hennessy Clinical Research Directorate/Clinical Monitoring Research Program, Leidos Biomedical Research, Inc., Frederick National Laboratory for Cancer Research, 5705 Industry Lane, Frederick, MD 21704, USA

Tel +l 2405294268

Fax +I 2402767907

Email erin.hennessy@fnlcr.nih.gov
Abstract: Evidence suggests that regular family meals protect against unhealthy eating and obesity during childhood and adolescence. However, there is limited information on ways to promote family meals as part of health promotion and obesity prevention efforts. The primary aim of this review was to synthesize the literature on strategies to promote family meals among families with school-aged children and adolescents. First, we reviewed interventions that assess family meals as an outcome and summarized strategies that have been used in these interventions. Second, we reviewed correlates and barriers to family meals to identify focal populations and target constructs for consideration in new interventions. During May 26-27, 2014, PubMed and PsycInfo databases were searched to identify literature on family meals published between January 1, 2000 and May 27, 2014. Two reviewers coded 2,115 titles/abstracts, yielding a sample of 139 articles for full-text review. Six interventions and 43 other studies presenting data on correlates of or barriers to family meals were included in the review. Four interventions resulted in greater family meal frequency. Although there were a small number of interventions, intervention settings were diverse and included the home, community, medical settings, the workplace, and the Internet. Common strategies were goal setting and interactive group activities, and intervention targets included cooking and food preparation, cost, shopping, and adolescent influence. Although methodological nuances may contribute to mixed findings, key correlates of family meals were employment, socioeconomic and demographic factors, family structure, and psychosocial constructs. Barriers to consider in future interventions include time and scheduling challenges, cost, and food preferences. Increasing youth involvement in mealtime, tailoring interventions to family characteristics, and providing support for families experiencing time-related barriers are suggested strategies for future research.

Keywords: family meals, families, intervention, diet

\section{Introduction}

Many aspects of the family and home environment are important influences on children's healthy eating ${ }^{1-3}$ and remain influential in adolescence, despite growing independence and influence of peers. ${ }^{4-6}$ One aspect of the home environment that shows promise in promoting healthy eating behaviors is engagement in family meals. In a meta-analysis, Hammons and Fiese ${ }^{7}$ concluded that family meal frequency contributes to a reduced likelihood of unhealthy eating, and a greater likelihood of healthy eating, among children and adolescents. Positive associations between family meals and healthy eating behaviors have also been found in systematic reviews. ${ }^{8,9}$ In one review, Woodruff and Hanning found that family meals generally have positive influences on adolescents' dietary intake, including fruit/vegetable consumption, dairy consumption, and less 
consumption of sugar-sweetened beverages and unhealthy foods. ${ }^{8}$ A second review, conducted by Fulkerson et al, found that positive effects of family meals on diet are evident among both youth and adults, demonstrating the importance of family meals during multiple developmental periods. ${ }^{9}$

Frequent family meals may also prevent obesity. Although inconsistencies across studies necessitate further research to clarify the association between family meal frequency and weight outcomes,,${ }^{9,10}$ a recent meta-analysis found that children and adolescents who had regular family meals were less likely to be overweight. ${ }^{7}$ Furthermore, a recent longitudinal analysis of data from Project EAT-III (Eating and Activity with Teens) found that eating family meals during adolescence was associated with a lower likelihood of being overweight or obese 10 years later, particularly for African American respondents. ${ }^{11}$ Beyond eating behaviors and obesity, family meals can contribute to reductions in substance use, violence, sexual activity, mental health issues, and self-harm among children and adolescents. ${ }^{12,13}$ Family meals also promote positive family interactions (including family communication, child socialization, and the transmission of values and culture). ${ }^{14}$

These prior literature reviews have focused on family meals' influence on behavior and well-being. Despite many published studies that have found family meals to have a positive influence on health and behavior, to our knowledge, there has been no synthesis of this work through literature reviews on intervention strategies to promote family meals or correlates and predictors of family meal engagement. Given existing evidence that family meals can have several health, social, and psychological benefits, an important next step is understanding opportunities to encourage family meals as part of efforts to encourage these positive outcomes. This knowledge is crucial in light of evidence that family meals show promise as part of larger efforts to promote healthy diet and prevent obesity.

The goal of the current paper was to review the existing family meals literature that is relevant to strategies to encourage more frequent family meals. In pursuit of this goal, the primary aim was to review existing interventions that assess family meal frequency as an outcome. In reviewing these interventions, we aimed to summarize the state of the literature on strategies that have successfully promoted engagement in family meals. We further aimed to investigate the scope of strategies and settings that have been used, and populations targeted, to identify promising approaches and research gaps in current family meals intervention research. The secondary aim was to review key correlates of and barriers to family meals from both quantitative and qualitative literature to identify constructs to acknowledge in family meal interventions. Unlike prior literature reviews, we focused on reviewing the factors that contribute to whether or not a family frequently shares meals together, rather than on reviewing the associations between family meals and behavioral outcomes.

\section{Methods}

\section{Search strategy}

We searched PubMed and PsycInfo to identify a broad selection of literature on family meals, since there are variations in how family meals are operationalized across studies. ${ }^{10}$ Database searches were conducted during May 26-27, 2014 and included keywords at three levels: 1) youth/adolescence (adolescent OR adolescence OR teen OR teenager OR youth OR boys OR girls OR "middle school" OR "high school" OR child OR children), 2) mealtimes (meal* OR dinner* OR lunch* OR breakfast*), and 3) family (family OR "parentchild relations" OR "family relations" OR parent* OR mother* OR father*). Keywords were informed from prior reviews related to family meals. ${ }^{7,10,12,13}$ The aim of the mealtime search terms was to capture relevant studies across a variety of definitions of family meals. Studies differ as to whether they assess family meals in general (versus focusing specifically on family dinners, breakfasts, or lunches), as well as whether family meals are youth- or parent reported, the location of the family meal, and the number of family members that defines a "family meal". ${ }^{10}$ We reviewed studies regardless of these methodological differences. However, we focused specifically on shared meals between parents/caregivers and children, rather than shared meals among families without children.

In PubMed, search terms that were also Medical Subject Headings (MeSH) were searched as both individual terms and MeSH keywords ("adolescent", "meals", “dinner", "lunch", "breakfast", "family", "parent-child relations", "family relations", "parents", "mothers", "fathers"). The full texts of articles needed to include at least one word from each level of the search. We limited searches in both databases to results that were peer reviewed, conducted with human populations, written in English, and published between January 1, 2000 and May 27, 2014. The PsycInfo search was limited to peer-reviewed journal articles, and we checked results from PubMed for peer-reviewed sources.

\section{Review procedure}

Figure 1 describes each step of the review process. After identifying all unique search results, two reviewers (EH and LD) completed the review of titles/abstracts and full-text pdfs. 


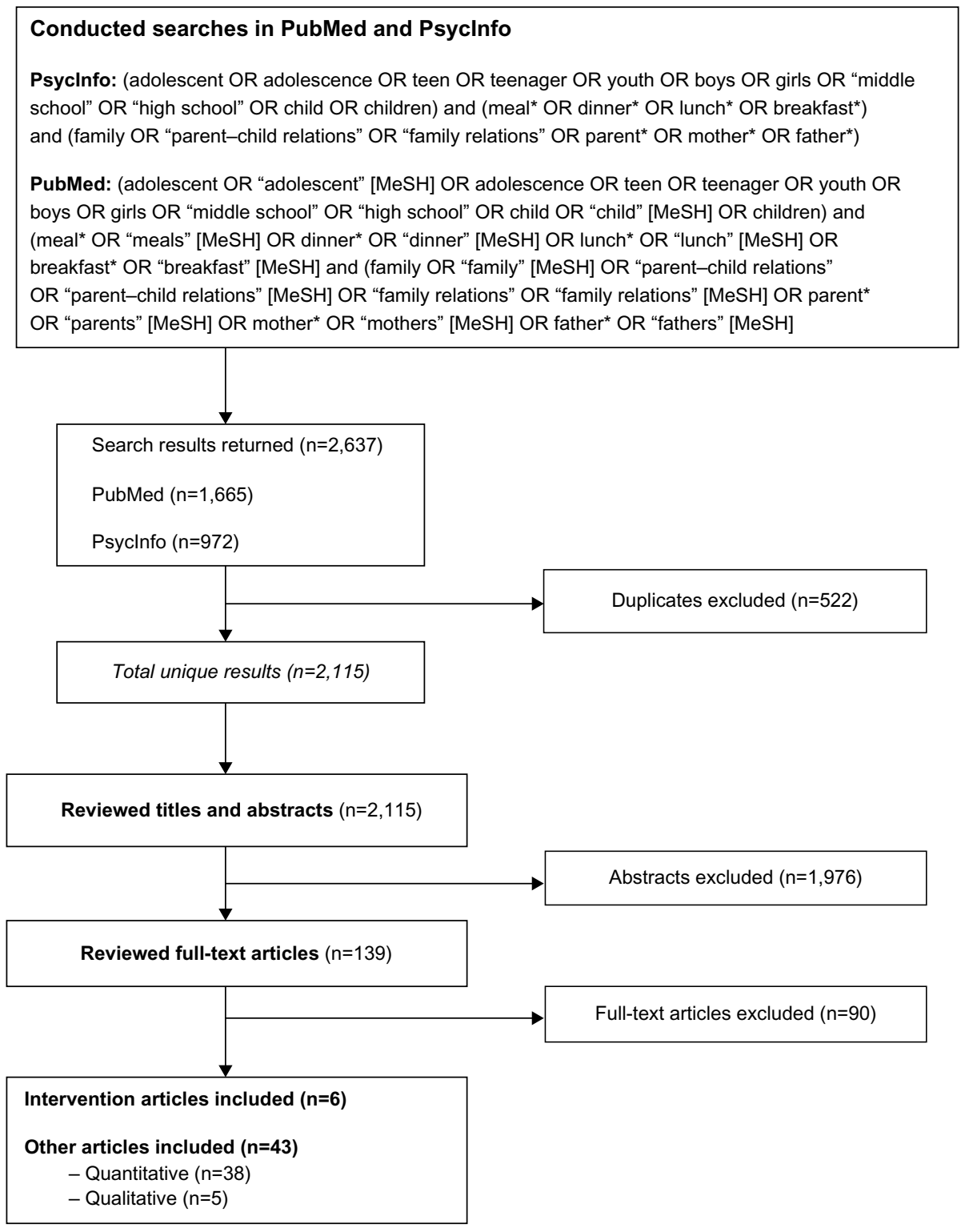

Figure I Literature review methodology and results.

Abbreviation: MeSH, Medical Subject Headings.

\section{Review of titles and abstracts}

Each reviewer independently coded each of 2,115 titles/ abstracts and met to reach agreement on any discrepancies. During the abstract review stage, we coded for inclusion most abstracts that specifically mentioned family meals or strongly suggested a social component surrounding mealtimes. All abstracts that described interventions which targeted or assessed family meals or similar constructs (eg, meal-related parenting practices/family behaviors, or youth involvement in meals) were coded for inclusion in the full-text round of the review. We also included articles that mentioned family meals or social components of mealtimes outside of an intervention context (including both quantitative and qualitative studies), so as to broadly capture articles that could include data on correlates of family meals. There were four exceptions that caused otherwise relevant abstracts to be excluded at this stage of the review. First, since family meals' associations with eating behaviors, weight, and other behavioral outcomes have been the topic of prior literature reviews, we excluded abstracts which focused on family meals' influence on these constructs. Second, while we reviewed interventions regardless of child's age (to comprehensively capture all interventions to date), we excluded abstracts from correlational and qualitative research that focused on children whose mean age was younger than five. Third, we excluded abstracts that focused on populations with anorexia, bulimia, 
eating disorders not otherwise specified, feeding problems, or other diagnoses except overweight and obesity. Fourth, we excluded literature reviews and articles that were not original studies, even if they focused on family meals. These criteria resulted in the exclusion of 1,976 abstracts, leaving 139 remaining articles for full-text review.

\section{Review of full-text articles}

Consistent with the primary aim, we first reviewed the full texts of intervention studies. Intervention articles were included if they assessed family meal frequency among the intervention outcomes and described intervention results. Using these criteria, we identified six articles. From each of these articles, we summarized the following data: authors/ year, country, sample characteristics (for parent and youth), theory, research design, intervention content, measurement of family meals, intervention effects on family meals, and statistically significant intervention effects on other outcomes.

After completing our full-text review, we took two approaches to check that we captured all relevant interventions. First, we conducted a supplementary search for articles that described intervention methodology without reporting on intervention outcomes to determine whether any other publications using intervention data reported on results related to family meals. Second, the reference lists of eight relevant literature reviews were scanned for additional interventions. Neither of these secondary methods returned additional articles for inclusion.

To meet the secondary aim, we reviewed the full texts of quantitative and qualitative articles examining correlates of and barriers to family meals. Quantitative articles were included if they had 1) an assessment of family meals as reported by a sample of school-aged youth and/or their parents, and 2) a statistical analysis of the association between family meal frequency and at least one other construct other than diet, weight, well-being, or other behavioral outcomes. We identified 38 quantitative articles for inclusion. We summarized constructs related to family meals and their association (positive, negative, and/or nonsignificant) across this set of articles. Qualitative articles were scanned to provide additional insights into barriers and suggested ways to promote family meals. To be included, qualitative studies needed to focus specifically on family meals. We identified five qualitative articles for inclusion.

\section{Results}

Our review identified six intervention studies meeting our inclusion criteria, four of which successfully promoted family meal frequency. The interventions, which are described in detail in the following section, represented a range of intervention settings and techniques. Thirty-eight additional quantitative studies examined associations between family meal frequency and several other constructs, including those related to demographics, employment, family structure, psychosocial variables, and the home environment. Finally, five qualitative articles provided further data on barriers and facilitators to engagement in family meals.

\section{Intervention studies}

\section{Interventions promoting family meal frequency}

Of the six articles, four presented statistically significant intervention effects on family meal frequency. One intervention was delivered to 8,618 clients of the Special Supplemental Nutrition Program for Women, Infants, and Children (WIC) in Washington State. ${ }^{15}$ This intervention involved a module promoting family meals which was tailored to clients' stage of change and delivered across 6 months by trained staff. Although family meal frequency was high regardless of condition, clients in agencies that received the family meals module reported more frequent family meals (assessed as the number of family meals during the past 7 days) over the course of the intervention (an increase of $2 \%$ ). However, clients in WIC agencies that were assigned to a physical activity module had a $4 \%$ decrease in family meals during the intervention.

A second large-scale intervention was delivered via the Internet to 22,265 IBM Corporation employees with children (mean child age $=9.3$ ). ${ }^{16}$ This 12 -week program was provided to employees who enrolled for a cash incentive and focused on healthy eating (including family meals), physical activity, screen time, and parent role modeling. Families were guided through identifying and monitoring their progress toward behavioral goals in these areas, and they received online planners, tools, and recipes. Over the course of the program, the percentage of participants reporting their family eats healthy family meals on five or more days per week increased by $8.3 \%$ (from $48.8 \%$ to $57.1 \%$ ).

Two smaller-scale interventions also successfully promoted family meals. Rosenkranz and Dzewaltowski ${ }^{17}$ reported on a 4-week intervention for 100 girls (aged 6-12) attending a summer program. All girls received one 2-hour intervention session per week that promoted abilities to contribute to healthy family mealtimes, including cooking, preparing fruits and vegetables, and asking parents for healthy mealtime changes (eg, drinking water and eating fruits and vegetables during meals). After making changes at home, 
participants received jewelry beads to remind themselves of the skills learned in the program. A subsample of the girls' mothers $(n=30)$ reported in a follow-up survey that their family meal frequency (assessed with four items) was higher post-intervention.

Another intervention, reported by DeBar et al, ${ }^{18}$ was implemented in a primary care setting within a program for teens (mean age $=14.1$ ) who had an age- and sexadjusted body mass index (BMI) percentile $\geq 90$. Participants attended a total of 1690 -minute group sessions over 5 months. Sessions focused on healthy eating (including family meals), physical activity, issues surrounding mental health, body image, and disordered/emotional eating, and the development of coping strategies and behavioral goals. Parents attended weekly meetings over 3 months which focused on promoting family meals and positive family interactions. Pediatricians also met with participants at baseline and at the 6-month follow-up to further support behavioral goals. Twelve months after baseline, participants in the intervention condition reported less of a decrease in family meals per week (from 3.85 to 3.51 average meals per week), as compared to control participants who only received informational materials and a baseline visit with their primary care doctor (4.34 to 3.29 meals per week).

\section{Interventions unrelated to family meal frequency}

Two interventions were not significantly related to family meals, although they had positive effects on other measured outcomes (Table 1). Ayala et a $1^{19}$ reported on an intervention delivered in the home to 366 families ( $71 \%$ Latino) with a child in grades K-2 (median child age $=6$ ). Families received home visits by promotoras for 7 months, followed by four follow-up phone calls and mailings for the next 2 years, although $23 \%$ of parents opted to receive all study materials via mail. Intervention strategies included parental goal setting, delivery of printed materials, and discussions about healthy eating and physical activity, but the intervention did not influence the number of family meals (defined as the sum of whether the family eats breakfast, lunch, and dinner as a family four or more times per week).

Finally, Fulkerson et $\mathrm{al}^{20}$ reported on the results of a pilot study, "Healthy Home Offerings via the Mealtime Environment", which was administered to 22 dyads of parents and their 8- to 10-year-old children. Dyads participated in five 90-minute sessions with other families in a church and/or community center. Sessions each focused on a unique topic related to healthy eating and involved a snack and group meal, as well as several interactive activities. Activities centered on meal preparation, nutrition education, separate discussions/ activities for parents and children, and materials to complete at home. Although children in the intervention group more often helped their parents prepare dinner, there were no significant post-intervention differences between intervention and control dyads in family dinner frequency (defined as the number of family dinners per week).

Finally, there were several intervention studies that were related to family meals but did not meet all of the inclusion criteria. Articles were excluded if they: reported on baseline data only, described intervention design or methods without reporting intervention outcomes, or did not assess family meal frequency as an outcome. Supplemental searches revealed that one intervention mentioned in an article reporting only baseline data ${ }^{21}$ was also discussed in another article reporting intervention results. ${ }^{22}$ While this article presented a nonsignificant intervention effect on family meals in a results table, further description of family meals' definition and assessment was not provided in the text. Therefore, we did not include this article in Table 1.

\section{Correlates of and barriers to family meals: quantitative studies}

Tables 2-5 summarize all correlates and barriers identified in the review. As evident in these tables, some constructs have been examined in only a limited number of studies or have been inconsistently associated with family meals within or across studies. To succinctly summarize the constructs that should be considered in future intervention design, we summarize in the following sections only the correlates that were significantly associated with family meals in two or more of the studies.

\section{Demographics}

In nine studies, child sex was unrelated to family meal frequency. ${ }^{23-31}$ However, in two studies, male child sex was associated with greater reported frequency of family meals. ${ }^{32,33}$ One other study found male child sex to be associated with fewer reported family meals, ${ }^{34}$ and one found mixed results depending on variables in the statistical model. ${ }^{35}$ Younger child age was a statistically significant correlate of more frequent family meals in six studies ${ }^{23,25,27,29,33,34}$ but was unrelated to family meals in four studies. ${ }^{26,30,31,36} \mathrm{In}$ two studies, older parent age was associated with fewer family meals, ${ }^{29,37}$ but this association was not significant in two studies $^{36,38}$ and mixed in a third study. ${ }^{31}$

While several studies did not find any association between race/ethnicity and family meal frequency, $28,30,39,40$ 


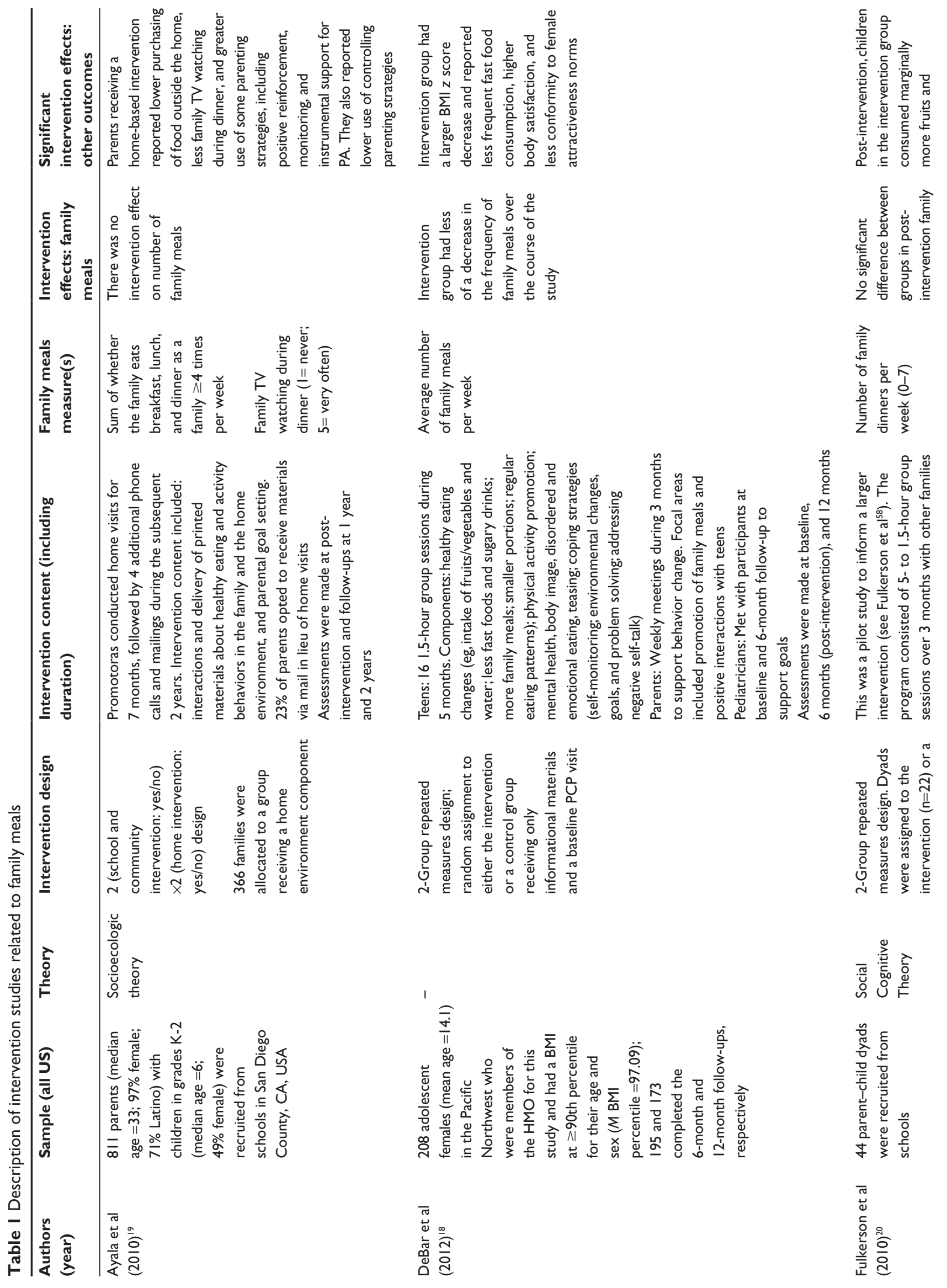




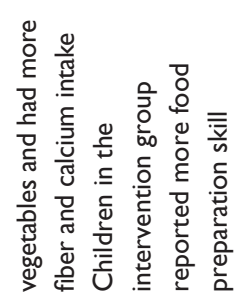
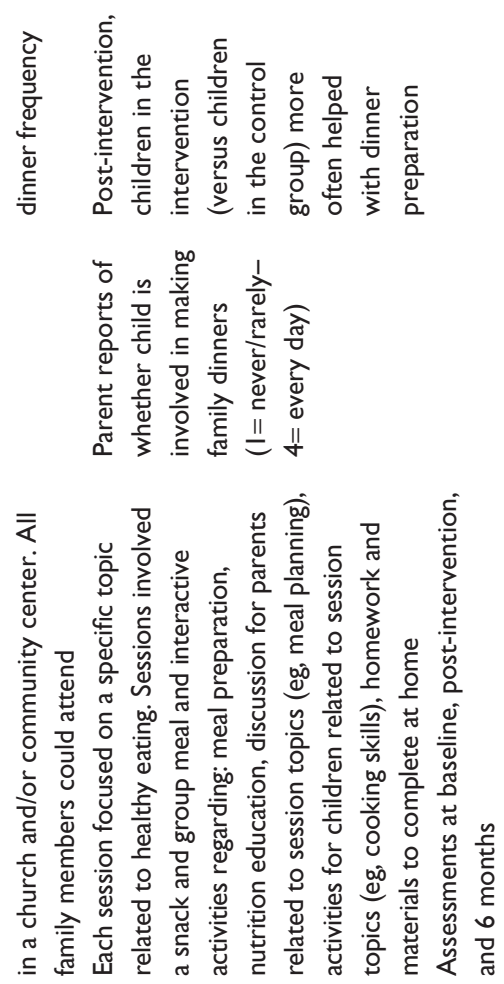

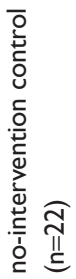

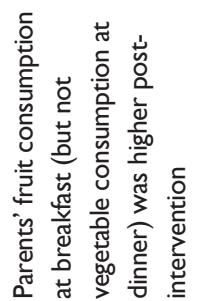

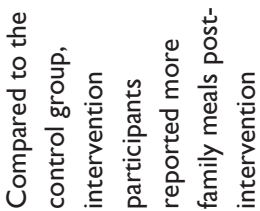

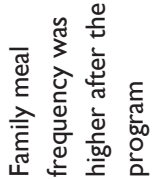

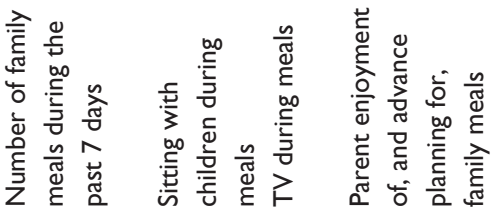

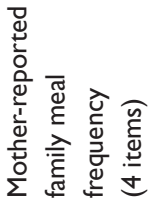

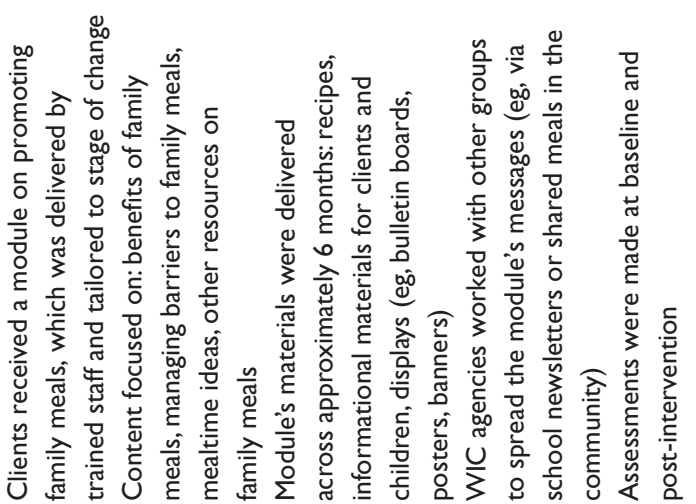

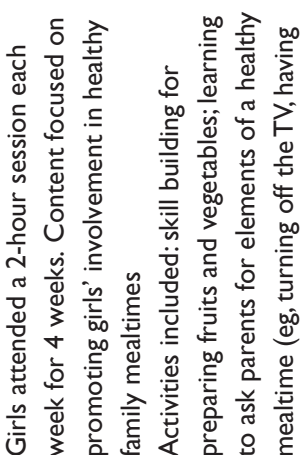

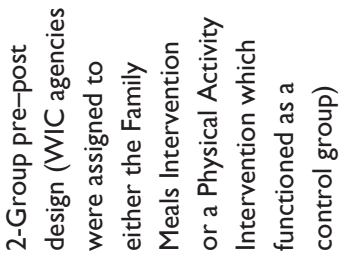

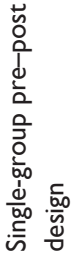

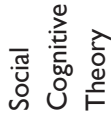

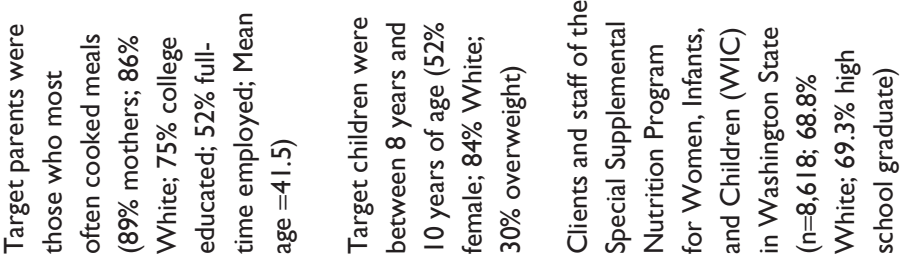

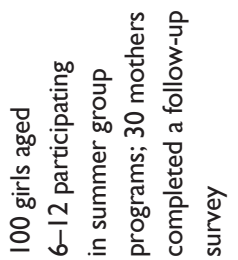

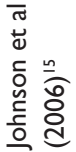

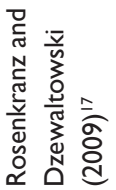




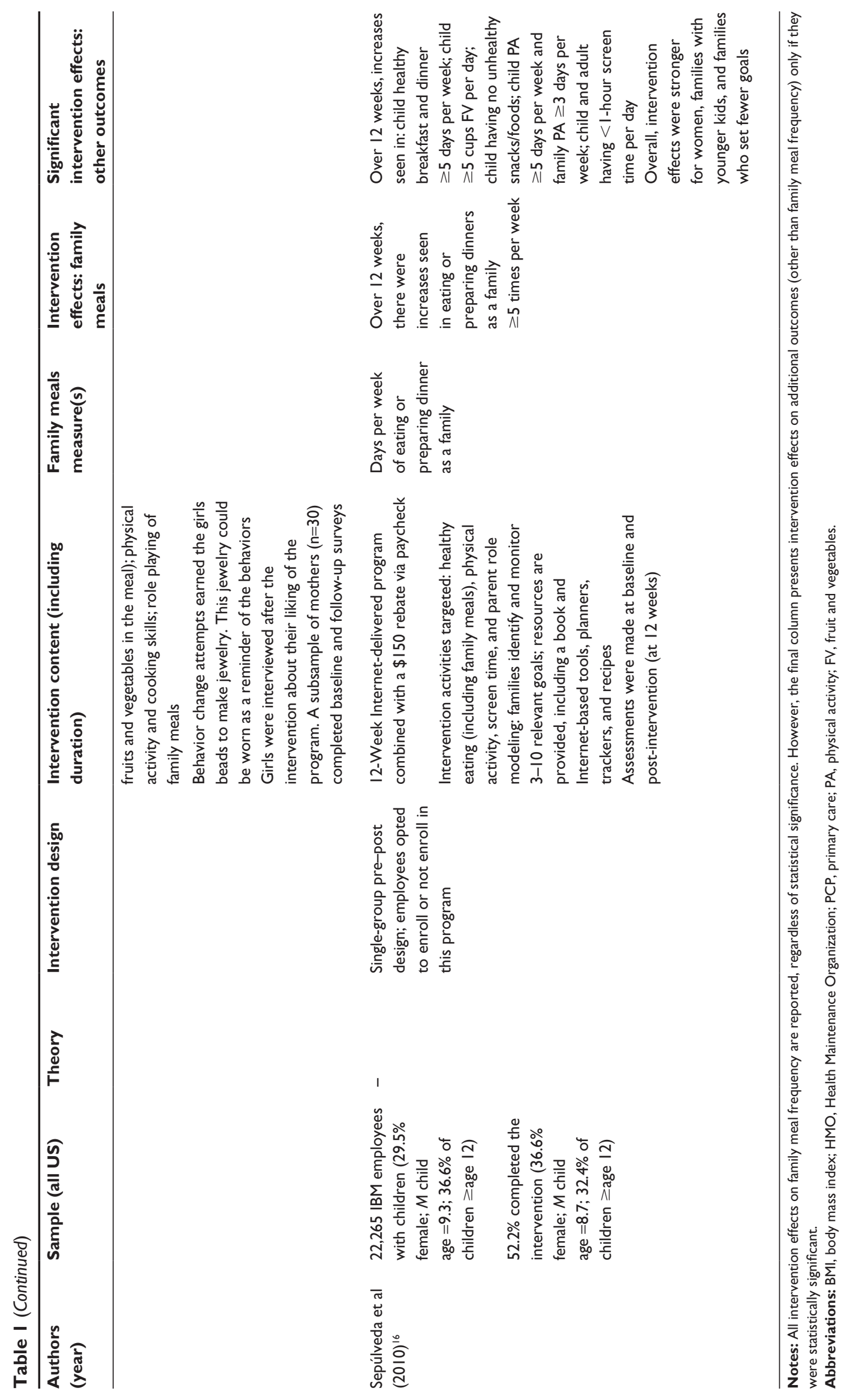


Table 2 Demographic and family structure correlates of family meal frequency

\begin{tabular}{|c|c|c|c|}
\hline Category & Correlate & References & Association \\
\hline \multirow[t]{28}{*}{ Demographics } & \multirow[t]{4}{*}{ Child sex (male) } & 32,33 & + \\
\hline & & $23-31$ & 0 \\
\hline & & 34 & - \\
\hline & & 35 & -10 \\
\hline & \multirow[t]{2}{*}{ Parent sex (male) } & 37 & - \\
\hline & & 38 & -10 \\
\hline & \multirow[t]{3}{*}{ Parent age } & 36,38 & 0 \\
\hline & & 29,37 & - \\
\hline & & 31 & -10 \\
\hline & \multirow[t]{2}{*}{ Child age } & $22,25,27,29,33,34$ & - \\
\hline & & $26,30,31,36$ & 0 \\
\hline & Race/ethnicity & 33 & + \\
\hline & (Asian) & 31 & +10 \\
\hline & $\begin{array}{l}\text { Race/ethnicity } \\
\text { (Hmong) }\end{array}$ & 62 & + \\
\hline & $\begin{array}{l}\text { Race/ethnicity } \\
\text { (Black/African } \\
\text { American) }\end{array}$ & $23,26,29$ & - \\
\hline & $\begin{array}{l}\text { Race/ethnicity } \\
\text { (Hispanic/Latino) }\end{array}$ & 26,29 & 0 \\
\hline & $\begin{array}{l}\text { Race/ethnicity } \\
\text { (Black or Hispanic) }\end{array}$ & 31 & - \\
\hline & $\begin{array}{l}\text { Race/ethnicity } \\
\text { (general) }\end{array}$ & $28,30,39,40$ & 0 \\
\hline & Child non-US & 40 & + \\
\hline & \multirow[t]{2}{*}{ nativity } & 28 & 0 \\
\hline & & 62 & +10 \\
\hline & $\begin{array}{l}\text { Length of time } \\
\text { in US }\end{array}$ & 28 & 0 \\
\hline & \multirow{3}{*}{ Rural location } & 38 & 0 \\
\hline & & $24,4 I$ & + \\
\hline & & 35 & +10 \\
\hline & $\begin{array}{l}\text { Geographical } \\
\text { region of US }\end{array}$ & 29 & 0 \\
\hline & $\begin{array}{l}\text { Living in refugee } \\
\text { camps }\end{array}$ & 24 & - \\
\hline & $\begin{array}{l}\text { Religious affiliation } \\
\text { (conservative } \\
\text { Protestant) }\end{array}$ & 29 & +10 \\
\hline Socioeconomic & Socioeconomic & 35 & - \\
\hline \multirow[t]{10}{*}{ status } & status & 33 & + \\
\hline & \multirow[t]{5}{*}{ Parent education } & 26,40 & + \\
\hline & & 31 & $+1-$ \\
\hline & & $28,37,39$ & 0 \\
\hline & & 42 & +10 \\
\hline & & 35 & -10 \\
\hline & \multirow[t]{3}{*}{ Parent income } & 26 & - \\
\hline & & 31 & $+1-$ \\
\hline & & $29,36,37,39$ & 0 \\
\hline & Food insecurity & 63 & - \\
\hline \multirow[t]{2}{*}{ Family structure } & Married and/ & 39 & + \\
\hline & $\begin{array}{l}\text { or cohabitating } \\
\text { parents }\end{array}$ & 28,29 & 0 \\
\hline
\end{tabular}

(Continued)
Table 2 (Continued)

\begin{tabular}{llll}
\hline Category & Correlate & References & Association \\
\hline & Having both & 26 & + \\
biological parents/ & 31,38 & $+/ 0$ \\
two parents in & & \\
household & & \\
& Number of children & $26,38,39$ & + \\
& in family & 28 & 0 \\
\hline
\end{tabular}

Notes: "+" = statistically significant positive association; "-" = statistically significant negative association; " 0 " = no significant association. Mixed findings include studies where associations differed across subsamples, measures, or different statistical models.

there were several exceptions. For example, three studies found that family meals were less frequent among African Americans, ${ }^{23,26,29}$ and one study found that family meals were less frequent among African Americans and/or Hispanics. ${ }^{31}$ One study found family meals to be more frequent among Asians, ${ }^{33}$ although this association was mixed in a second study, depending on the type of family meal (breakfast or dinner). ${ }^{31}$

A limited number of studies examined urban versus rural location as a correlate of family meals. Two international studies found that families in rural locations reported more frequent family meals, ${ }^{24,41}$ while one study found a nonsignificant association..$^{38} \mathrm{~A}$ fourth study had mixed findings, in that there was a positive association between rural location and family meals at the bivariate level but not when other variables were included in the analysis. ${ }^{35}$

\section{Education}

While two studies found positive associations between parents' education and family meals, ${ }^{26,40}$ two found no significant association. ${ }^{28,39}$ Three studies found mixed results. ${ }^{31,35,42}$ For example, one study found a positive association for boys but not for girls, ${ }^{42}$ while another found a negative association at the bivariate level but a nonsignificant association in further analyses, ${ }^{35}$ and a third found the association to vary depending on whether the outcome was family breakfasts or family dinners. ${ }^{31}$

\section{Family structure}

In two studies, having married/cohabitating parents or two parents in the household was positively associated with family meals. ${ }^{26,39}$ In one other study, having a dual-parent household was associated with greater time eating with children but was unrelated to time spent eating with children specifically during the weekdays. ${ }^{38}$ In another study, having two biological parents in the household was associated with greater family breakfast frequency but was unrelated to family dinners. ${ }^{31}$ 
Table 3 Employment-related correlates of family meal frequency

\begin{tabular}{|c|c|c|c|}
\hline Category & Correlate & References & Association \\
\hline Parents' time in & Mothers' employment (versus unemployment) & 44 & 0 \\
\hline \multirow[t]{20}{*}{ employment } & & $26,28,33,43$ & - \\
\hline & & 35 & -10 \\
\hline & Parents' employment (versus unemployment) & 38 & - \\
\hline & Fathers' employment (versus unemployment) & 29 & 0 \\
\hline & Mothers' time in employment & 31,46 & - \\
\hline & Fathers' time in employment & 45 & - \\
\hline & & 29,46 & 0 \\
\hline & Parents' time in employment & 37 & -10 \\
\hline & & 38 & 0 \\
\hline & Both parents work $>20$ hours per week & 39 & - \\
\hline & Nonstandard/variable work hours/shift work & 29,45 & - \\
\hline & & 48 & 0 \\
\hline & & 47 & -10 \\
\hline & Mothers' working evening or night hours & 48,64 & - \\
\hline & Fathers' working evening or night hours & 48 & $+/ 0$ \\
\hline & & 64 & - \\
\hline & Flextime work policies & 37 & 0 \\
\hline & Flexplace work policies & 37 & $0 /+$ \\
\hline & Parents' work-life stress/interference & 37,46 & - \\
\hline & Supportive work supervisor & 37 & + \\
\hline Adolescent employment & Adolescent employment (versus no employment) & 44 & 0 \\
\hline
\end{tabular}

Notes: "+" = statistically significant positive association; “-” = statistically significant negative association; "0" = no significant association. Mixed findings include studies where associations differed across subsamples, measures, or different statistical models.

Table 4 Behavioral and psychosocial correlates of family meal frequency

\begin{tabular}{|c|c|c|c|}
\hline Category & Correlate & References & Association \\
\hline Parent behavior & Meal planning & 36 & + \\
\hline \multirow[t]{3}{*}{ Youth behavior } & Adolescent leisure activities & 42 & 0 \\
\hline & Smoking/social independence & 65 & - \\
\hline & Food preparation & 30 & 0 \\
\hline \multirow[t]{9}{*}{ Parent psychosocial } & Perceived importance of family meals & 34,36 & + \\
\hline & Perceived difficulty eating together due to time/schedules & 34 & - \\
\hline & Positive general perceptions toward family meals & 34 & $+/ 0$ \\
\hline & Time constraints on cooking & 36 & 0 \\
\hline & Importance of food cost & 36 & 0 \\
\hline & Preference for meals that are easy to prepare & 36 & 0 \\
\hline & Positive attitudes toward eating alone & 38 & - \\
\hline & Perception of child overweight & 66 & 0 \\
\hline & Sex traditionalism & 29 & 0 \\
\hline \multirow[t]{14}{*}{ Youth psychosocial } & Intention & 50 & + \\
\hline & Positive subjective norm for family meals & 50 & $+/ 0$ \\
\hline & Perceived difficulty eating together due to time/schedules & 30,34 & - \\
\hline & & 50 & -10 \\
\hline & & 49 & -10 \\
\hline & Positive attitudes toward family meals & 49,50 & $+/ 0$ \\
\hline & & 30,34 & + \\
\hline & Perceived importance of family meals & $30,34,36,44$ & + \\
\hline & & 49 & $+/ 0$ \\
\hline & Enjoyment of family meals & 30 & 0 \\
\hline & Want to eat family meals in future & 49 & + \\
\hline & Perceived different family food preferences & 49 & 0 \\
\hline & Perceived conflict at mealtimes among family & 49 & 0 \\
\hline & Cooking self-efficacy & 30 & + \\
\hline
\end{tabular}

Notes: "+" = statistically significant positive association; "-" = statistically significant negative association; "0" = no significant association. Mixed findings include studies where associations differed across subsamples, measures, or different statistical models. 
Table 5 Home environmental correlates of family meal frequency

\begin{tabular}{llll}
\hline Category & Correlate & References & Association \\
\hline Home & Fruit and vegetables/ & $5 \mathrm{I}$ & + \\
environment & healthy food availability & 49 & $+/-$ \\
& at home & & + \\
& Family functioning & 32 & $+/ 0$ \\
& Authoritative parenting & 67 & $+/ 0$ \\
& Feeding styles & 28 & \\
(high demanding/high & & + \\
& responsive) & & $0 /+$ \\
& Greater mealtime rules & 49 & + \\
& & 34 & - \\
& Meals as a daily routine & 49 & 0 \\
& TV during meals & 28,34 & + \\
& & 30 & \\
& Time spent in other & 68 & \\
joint family activities & &
\end{tabular}

Notes: "+" = statistically significant positive association; “-” = statistically significant negative association;"0" = no significant association. Mixed findings include studies where associations differed across subsamples, measures, or different statistical models.

In two other studies, the association between marital status and family meals was not significant. ${ }^{28,29}$ In three studies, number of children in the household corresponded to more frequent family meals, ${ }^{26,38,39}$ but another study found this association to be nonsignificant. ${ }^{28}$

\section{Employment and workplace}

Several factors related to parents' employment and workplace environments have been examined in prior literature. Mothers' employment was negatively associated with family meal frequency in four of the studies that we reviewed. . $^{26,28,33,43}$ However, associations were nonsignificant in one study ${ }^{44}$ and mixed in another study. ${ }^{35}$ Parents' time in employment was negatively associated with family meal frequency in several studies. ${ }^{31,39,45}$ In two studies, there were mixed findings. ${ }^{37,46}$ In two other studies, there was no significant association between time in employment and family meals. ${ }^{29,38}$ There was also evidence that having nonstandard or variable work hours was associated with reduced family meal frequency, ${ }^{29,45}$ although one study found that this association varied by length of follow-up ${ }^{47}$ and another found the association to be nonsignificant. ${ }^{48}$ In two studies, parents' work-life stress/ interference was negatively associated with family meal frequency. ${ }^{37,46}$

\section{Psychosocial variables}

Both parents' and adolescents' perceived importance of family meals was consistently associated with family meal frequency, ${ }^{30,34,36,44}$ with the exception of one study in which the association was significant for female, but not male, adolescents. ${ }^{49}$ Perceived difficulty of eating together due to time and/or schedules was negatively correlated with family meals across two studies, ${ }^{30,34}$ although one other study found differences in this association by child sex (significant for females only), and by type of schedule (parent work versus child activities), ${ }^{50}$ and another one of the studies also found mixed results. ${ }^{49}$ In two studies, general positive attitudes/ perceptions toward family meals were associated with greater family meal frequency. ${ }^{30,34}$

\section{Home environment}

Other aspects of the home environment were also studied in relation to family meals. Two studies found that watching TV during meals was negatively associated with engagement in family meals, ${ }^{28,34}$ although one study found this association to be nonsignificant. ${ }^{30}$ There was also some evidence for a positive association between having greater mealtime rules overall and engagement in family meals, ${ }^{34,49}$ although Fulkerson et $\mathrm{al}^{34}$ found that this association was significant only for adolescent reports (not parent reports). Two studies found that healthy food availability in the home was positively associated with family meal frequency, ${ }^{49,51}$ although in one study, this was significant only among females. ${ }^{49}$

\section{Benefits of and barriers to family meals: qualitative studies}

We identified five qualitative studies focused on family meals that provided additional insight into barriers, facilitators, and strategies of family meals (as seen in Table 6). Four of the five studies focused on parents, ${ }^{53-56}$ while only one study focused on adolescent perception of family meals. ${ }^{52}$ Consistency across studies suggests that parents are aware of many (but perhaps not all) benefits of family meals including increased communication, strengthening of interpersonal relationships, opportunity to model healthy behaviors, and the provision of structure and routines. However, these benefits were challenged in many ways. Time constraints driven by work obligations, shift work, and adolescent extracurricular activities interfered with family meals. Many parents felt too tired or burdened to provide routine family meals or were challenged by the various food preferences within the family and cost of providing family meals. Of particular interest is one study targeting adolescents, which raised additional challenges to family meals not mentioned by parents specifically including adolescent desire for autonomy and dissatisfaction with family relations. ${ }^{52}$

To address some of these challenges, families often multitasked (eg, prepared meal, helped with homework, sorted 


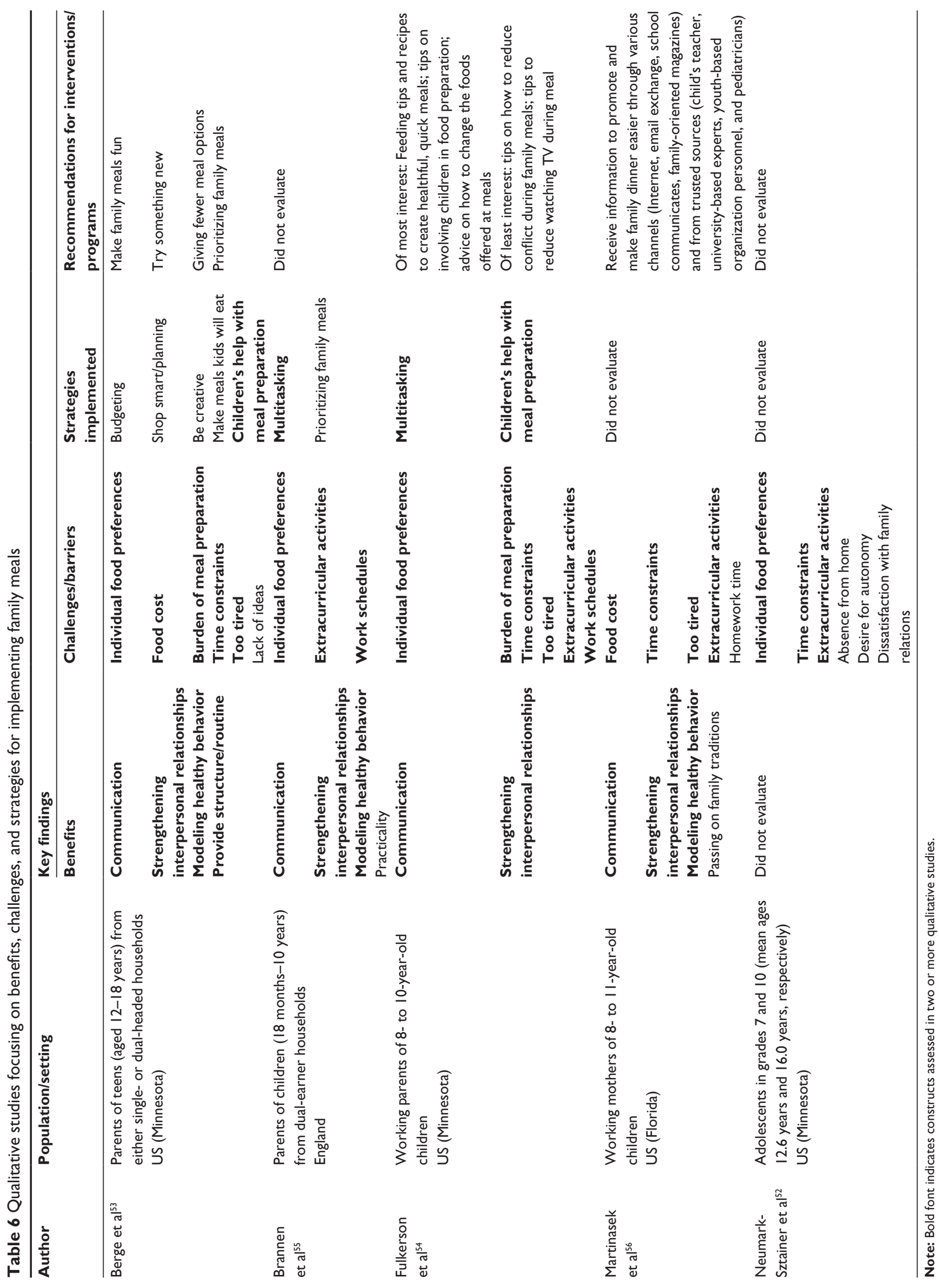


through school materials) and/or engaged children with their help in preparing meals. When prompted, parents suggested a number of possible intervention strategies to help promote family meals and the ways in which they could be engaged to promote family meals. Berge et $\mathrm{al}^{53}$ suggested that within family-based intervention programs, it may be important to tailor messages regarding family meal barriers according to family type. For single-headed households, it would be important to focus on budgeting and low-cost meals, whereas for dual-headed households, the messages could focus on creative meals and child involvement. Interventions targeting providers could in turn have providers give information to families about the ways in which families can benefit from family meals, deal with challenges to family meals, and provide suggestions for increasing family meals, based on family structure. ${ }^{53}$ Fulkerson et $\mathrm{al}^{54}$ suggested the need for nutrition education interventions and programs that 1) provide resources for quick and healthful meals and meal planning, 2) provide reminders to serve raw fruits and vegetables to reduce preparation time, and 3) educate parents on the importance of eating with their children to serve as role models and the positive nutritional benefits and life skill building associated with children's participation in meal preparation.

\section{Discussion}

The six intervention articles reviewed used multiple strategies in efforts to promote family meals, among other outcomes. In four out of six interventions, family meal frequency was promoted as a result of the intervention. Successful interventions were varied in setting, and involved promoting youth involvement in family meals over the course of a 4-week program, ${ }^{17}$ delivering a 6 -month family meals module to clients of WIC agencies, ${ }^{15} 6$ months of group sessions for teens, accompanied by support from parents and pediatricians for overweight teens, ${ }^{18}$ and a 12 -week online program delivered to employees. ${ }^{16}$ Interventions, including those that both did and did not promote family meals, were implemented in several settings (home, community and medical settings, workplace, and the Internet), and varied as to whether they targeted the parent, adolescent, or family. Although varied, common intervention strategies included goal setting and group activities for parents and children. Intervention targets represented a diversity of factors contributing to family meals, including cooking and food preparation, cost, shopping, and adolescent influence.

These interventions suggest that it is possible to effectively increase family meals using various strategies.
However, the number of effective interventions is limited, they are variable in scope, and it is unknown how the strategies utilized in these studies would vary in impact across populations (including outside of the US) or in the context of other barriers to engagement in family meals. Identifying the correlates of and barriers to family meals can provide insight into the constructs and populations that should be prioritized in future interventions. The present review of quantitative literature revealed many correlates and barriers that may be considered when designing further family meal interventions, including demographics (child sex, ${ }^{32-35}$ child age, ${ }^{23,25,27,29,33,34}$ parent age ${ }^{29,37}$ race/ethnicity, ${ }^{23,26,29,31,33}$ location of residence, ${ }^{24,35,41}$ and parent education ${ }^{26,31,35,40,42}$ ), family structure (parent marital status ${ }^{26,31,38,39}$ and number of children in the household ${ }^{26,38,39}$ ), employment (mothers' employment, ${ }^{26,28,33,43}$ time parents spend working per week, ${ }^{31,39,45}$ having variable work schedules, ${ }^{29,45,47}$ and work-life stress ${ }^{37,46}$ ), psychosocial variables (perceived importance of family meals, ${ }^{30,34,36,44}$ perceived difficulty due to time or schedules, ${ }^{30,34,49,50}$ and family meal attitudes ${ }^{30,34}$ ), and the home environment (watching TV during meals, ${ }^{28,34}$ mealtime rules, ${ }^{34,49}$ and food availability $\left.{ }^{49,51}\right)$. The qualitative literature further demonstrated that time constraints and schedules are key barriers to family meals, ${ }^{52-56}$ in addition to cost, ${ }^{53,56}$ family food preferences, ${ }^{52,54,55}$ being too tired, ${ }^{53,54,56}$ the burden of meal preparation, ${ }^{53,54}$ and in a study of adolescents, desire for autonomy. ${ }^{52}$

\section{Designing new interventions}

Future research should consider multilevel determinants of family meals ${ }^{14}$ and whether and how to target these determinants through new interventions to promote frequent and sustained engagement in family meals. One way that the current intervention literature could be expanded upon is by targeting populations who experience more barriers to family meals. These populations may include families with older adolescents, ${ }^{23,25,27,29,33,34}$ as well as families with greater parental employment $26,28,29,31,33,37,39,43,45,46$ and/or perceptions of time commitments that conflict with mealtimes. ${ }^{30,34} \mathrm{Of}$ the six interventions reviewed, there was variation in scope; however, some interventions involved attendance in multiple out-of-home sessions. ${ }^{18,20}$ An intervention of this magnitude may be less beneficial for families who are juggling multiple time commitments, including full-time or variable employment. For these families, interventions delivered to parents remotely or in the workplace may be most feasible, as might interventions directed at youth. Youth-focused interventions may help promote greater adolescent involvement 
in meal preparation which can provide practical support for busy households.

In addition to considering barriers and time constraints, future work should consider how to develop tailored interventions for different types of families. It is unknown how the strategies in the six existing interventions would translate into greater family meals across various populations. An illustration of how intervention approaches may need tailoring based on family characteristics is provided by Berge et al, who found that single-headed households experienced barriers related to food cost, while dual-headed households were concerned more with having creative meals and child involvement in meal preparation. ${ }^{53}$ Given recent findings that socioeconomic gaps in family meal frequency may be widening over time,${ }^{57}$ it is particularly important to consider which intervention strategies will be most effective, and which behavioral changes most sustainable, across levels of economic resources. Doing so will be particularly important among families for whom food cost is a barrier to family meals. ${ }^{53,56}$ Second, characteristics of children and adolescents should be considered when tailoring interventions. Only one of the interventions studied to date focused on families with overweight and obese adolescents. ${ }^{18}$ Given the ultimate goal of reducing obesity, future research should examine whether and how different strategies are needed for family meal interventions with overweight youth. In addition, researchers should consider the proper timing of interventions to both promote family meals early in childhood and reduce decreases in family meals that occur during adolescence. At least one intervention found that effects were strongest among families with younger children, ${ }^{16}$ which demonstrates the importance of considering timing, changing family dynamics, and adolescents' interests in future research.

\section{Limitations and future research directions Limitations}

We focused this review on interventions and correlates of family meal frequency among relatively healthy populations of families with children. We therefore excluded subsets of articles that are relevant to family meals. First, we excluded studies of family meals among children with feeding problems or among individuals with eating disorders or medical diagnoses. However, medical or mental health conditions contribute to the diversity of families' mealtime experiences. We also excluded abstracts that focused on the influence of family meals on behavioral and health outcomes because they have been represented in prior literature reviews. However, it is likely that those studies include additional information on correlates of family meals, as well as moderators of family meals' influence to consider in future intervention development. Although we excluded studies on shared eating among the general adult population, evidence of positive effects of family meals and other shared meals during adulthood ${ }^{9}$ demonstrates the importance of considering whether and how to facilitate shared meals among adults, regardless of whether or not they are parents. Additionally, the small number of intervention articles assessing family meals limits the ability to compare methodology and rigor across a large number of interventions. Given the limited intervention research, the goal was to present all of the current intervention findings on family meals regardless of the study methods and scope. However, as this body of literature grows, future literature reviews would benefit from a more detailed discussion of the strength of each study's findings.

\section{Future research}

Few interventions promoting family meals have been studied, leaving many opportunities available for the development of new approaches. Future research should develop interventions to make mealtimes easier for specific subpopulations, including families with adolescents, families with two working parents or parents with long or variable work hours, or families that experience other scheduling difficulties or time constraints.

Future research will also benefit from further study into the nuanced findings of correlates of family meals, as well as measurement variations across studies. Studies differ in whether how family meals are defined and whether they are reported by parents or adolescents, which may obscure research findings. ${ }^{7,10}$ A challenge we experienced in summarizing correlates of family meals is the wide variety of populations, methodologies, and definitions utilized in this body of literature.

It is also of particular importance for future interventions to examine how promoting family meals ultimately impacts diet and obesity. Studies should investigate whether interventions have positive effects on both family meal frequency and obesity, and whether intervention outcomes on obesity can be partially explained via increases in or maintenance of family meals. The interventions included in the present review did result in several positive outcomes other than family meals, including, among others, reductions in teens' $\mathrm{BMI}^{18}$ and improved diet (fiber and calcium intake, ${ }^{20}$ fruit and vegetable consumption, eating a healthy breakfast/dinner, 
less consumption of unhealthy foods, ${ }^{16}$ and less fast food consumption $\left.{ }^{18}\right)$. However, there is a lack of data on whether interventions promoting family meals have subsequent influences on obesity. One paper not included in the present review ${ }^{58}$ described the methodology of an ongoing intervention aiming to prevent obesity, promote healthy eating and physical activity in children, and promote the frequency and nutritional quality of family meals and snacks. Family meal frequency will be among the outcomes assessed, in addition to BMI as the primary outcome measure. ${ }^{58}$ To the extent that family meals and obesity are concurrently assessed in intervention work, we can gain information as to whether interventions targeting family meals can be effective in reducing the risk of obesity.

Finally, it is important to recognize potential interpersonal conflict that could result from encouraging families to eat meals together. To date, it remains unclear whether family meals retain their positive influences among families who have less positive interactions, and/or whether promoting family meals among families with more interpersonal conflict can promote more positive interactions. ${ }^{7}$ Overall, it is important for future research to recognize the complexity of influences on youth's eating patterns when considering whether and how to encourage family meals. ${ }^{8,9}$ While the majority of the literature has focused most heavily on the parent, a few studies have focused on older children and adolescents. Understanding the interplay of parent and child factors in influencing family meals will provide useful insight, as will considering how social functions and meanings of eating influence the context of family mealtimes. Youth ascribe multiple meanings to food and eating, and shared eating is meaningful in promoting youth's social interactions. ${ }^{59,60}$ Furthermore, meanings of eating often evolve across life stages and cultural/generational contexts. ${ }^{60,61}$ Understanding individuals' and families' diverse beliefs about eating may foster the development of relevant interventions across populations.

\section{Conclusion}

Interventions to promote family meals are limited. While some effective interventions exist, efficacy in promoting family meals is variable. However, interventions reflect diverse possibilities for settings and strategies to consider building upon in further efforts to encourage family meals. Although methodological nuances may be contributing to mixed findings in the literature, quantitative research findings suggest that several factors are associated with family meals, including employment-related variables, socioeconomic and demographic factors, family structure, child age, and psychosocial constructs. Qualitative work suggests that barriers to consider in future interventions include time and scheduling challenges, cost, food preference, and adolescents' beliefs. Increasing youth involvement in mealtime, tailoring interventions to family characteristics, and providing support for families experiencing time-related barriers are suggested strategies for future research.

\section{Acknowledgments}

This project has been funded in whole or in part with federal funds from the National Cancer Institute, National Institutes of Health, under contract number HHSN261200800001E (Hennessy). The content of this publication does not necessarily reflect the views or policies of the Department of Health and Human Services, nor does mention of trade names, commercial products, or organizations imply endorsement by the US Government. Additional funding was provided through a Cancer Research Training Award from the National Cancer Institute (Dwyer).

\section{Disclosure}

The authors have no conflict of interest to report.

\section{References}

1. Couch SC, Glanz K, Zhou C, Sallis JF, Saelens BE. Home food environment in relation to children's diet quality and weight status. $J$ Acad Nutr Diet. 2014;114(10):1569-1579.

2. Patrick H, Nicklas TA. A review of family and social determinants of children's eating patterns and diet quality. J Am Coll Nutr. 2005;24(2): 83-92.

3. Vereecken C, Haerens L, De Bourdeaudhuij I, Maes L. The relationship between children's home food environment and dietary patterns in childhood and adolescence. Public Health Nutr. 2010;13(10A): 1729-1735.

4. Larson NI, Wall MM, Story MT, Neumark-Sztainer DR. Home/family, peer, school, and neighborhood correlates of obesity in adolescents. Obesity. 2013;21(9): 1858-1869.

5. te Velde SJ, ChinAPaw MJ, De Bourdeaudhuij I, et al. Parents and friends both matter: simultaneous and interactive influences of parents and friends on European schoolchildren's energy balance-related behaviours - the ENERGY cross-sectional study. Int J Behav Nutr Phys Act. 2014;11:82.

6. Pedersen S, Gronhoj A, Thogersen J. Following family or friends. Social norms in adolescent healthy eating. Appetite. 2015;86:54-60.

7. Hammons AJ, Fiese BH. Is frequency of shared family meals related to the nutritional health of children and adolescents? Pediatrics. 2011;127(6):e1565-e1574.

8. Woodruff SJ, Hanning RM. A review of family meal influence on adolescents' dietary intake. Can J Diet Pract Res. 2008;69(1):14-22.

9. Fulkerson JA, Larson N, Horning M, Neumark-Sztainer D. A review of associations between family or shared meal frequency and dietary and weight status outcomes across the lifespan. J Nutr Educ Behav. 2014;46(1):2-19.

10. Valdés J, Rodríguez-Artalejo F, Aguilar L, Jaén-Casquero MB, RoyoBordonada MÁ. Frequency of family meals and childhood overweight: a systematic review. Pediatr Obes. 2013;8(1):e1-e13. 
11. Berge JM, Wall M, Hsueh TF, Fulkerson JA, Larson N, NeumarkSztainer D. The protective role of family meals for youth obesity: 10-year longitudinal associations. J Pediatr. 2015;166(2):296-301.

12. Goldfarb S, Tarver WL, Sen B. Family structure and risk behaviors: the role of the family meal in assessing likelihood of adolescent risk behaviors. Psychol Res Behav Manag. 2014;7:53-66.

13. Skeer MR, Ballard EL. Are family meals as good for youth as we think they are? A review of the literature on family meals as they pertain to adolescent risk prevention. J Youth Adolesc. 2013;42(7):943-963.

14. Larson RW, Branscomb KR, Wiley AR. Forms and functions of family mealtimes: multidisciplinary perspectives. New Dir Child Adolesc Dev. 2006;(111):1-15.

15. Johnson DB, Birkett D, Evens C, Pickering S. Promoting family meals in WIC: lessons learned from a statewide initiative. J Nutr Educ Behav. 2006;38(3):177-182.

16. Sepúlveda MJ, Lu C, Sill S, Young JM, Edington DW. An observational study of an employer intervention for children's healthy weight behaviors. Pediatrics. 2010;126(5):e1153-e1160.

17. Rosenkranz RR, Dzewaltowski DA. Promoting better family meals for girls attending summer programs. J Nutr Educ Behav. 2009;41(1):65-67.

18. DeBar LL, Stevens VJ, Perrin N, et al. A primary care-based, multicomponent lifestyle intervention for overweight adolescent females. Pediatrics. 2012;129(3):e611-e620.

19. Ayala GX, Elder JP, Campbell NR, et al. Longitudinal intervention effects on parenting of the Aventuras para Niños study. Am J Prev Med. 2010;38(2):154-162.

20. Fulkerson JA, Rydell S, Kubik MY, et al. Healthy Home Offerings via the Mealtime Environment (HOME): feasibility, acceptability, and outcomes of a pilot study. Obesity. 2010;18(Suppl 1):S69-S74.

21. Welsh EM, French SA, Wall M. Examining the relationship between family meal frequency and individual dietary intake: does family cohesion play a role? J Nutr Educ Behav. 2011;43(4):229-235.

22. French SA, Gerlach AF, Mitchell NR, Hannan PJ, Welsh EM. Household obesity prevention: take action - a group-randomized trial. Obesity. 2011;19(10):2082-2088.

23. Granner ML, Sargent RG, Calderon KS, Hussey JR, Evans AE, Watkins KW. Factors of fruit and vegetable intake by race, gender, and age among young adolescents. J Nutr Educ Behav. 2004;36(4):173-180.

24. Lazarou C, Panagiotakos DB, Kouta C, Matalas AL. Dietary and other lifestyle characteristics of Cypriot school children: results from the nationwide CYKIDS study. BMC Public Health. 2009;9:147.

25. Neumark-Sztainer D, Story M, Ackard D, Moe J, Perry C. Family meals among adolescents: findings from a pilot study. J Nutr Educ. 2000;32(6):335-340.

26. Wight VR, Price J, Bianchi SM, Hunt BR. The time use of teenagers. Soc Sci Res. 2009;38(4):792-809.

27. Wurbach A, Zellner K, Kromeyer-Hauschild K. Meal patterns among children and adolescents and their associations with weight status and parental characteristics. Public Health Nutr. 2009;12(8):1115-1121.

28. Tovar A, Hennessy E, Must A, et al. Feeding styles and evening family meals among recent immigrants. Int J Behav Nutr Phys Act. 2013;10:84

29. Wilcox WB. Religion, convention, and paternal involvement. J Marriage Fam. 2002;64(3):780-792.

30. Woodruff SJ, Kirby AR. The associations among family meal frequency, food preparation frequency, self-efficacy for cooking, and food preparation techniques in children and adolescents. J Nutr Educ Behav. 2013;45(4):296-303.

31. Anderson PM. Parental employment, family routines and childhood obesity. Econ Hum Biol. 2012;10(4):340-351.

32. Berge JM, Wall M, Larson N, Loth KA, Neumark-Sztainer D. Family functioning: associations with weight status, eating behaviors, and physical activity in adolescents. J Adolesc Health. 2013;52(3):351-357.

33. Neumark-Sztainer D, Hannan PJ, Story M, Croll J, Perry C. Family meal patterns: associations with sociodemographic characteristics and improved dietary intake among adolescents. J Am Diet Assoc. 2003;103(3):317-322.
34. Fulkerson JA, Neumark-Sztainer D, Story M. Adolescent and parent views of family meals. J Am Diet Assoc. 2006;106(4):526-532.

35. El-Gilany AH, Elkhawaga G. Socioeconomic determinants of eating pattern of adolescent students in Mansoura, Egypt. Pan Afr Med J. 2012;13:22.

36. McIntosh WA, Kubena KS, Tolle G, Dean WR, Jan JS, Anding J. Mothers and meals. The effects of mothers' meal planning and shopping motivations on children's participation in family meals. Appetite. 2010;55(3):623-628.

37. Allen TD, Shockley KM, Poteat LF. Workplace factors associated with family dinner behaviors. J Vocat Behav. 2008;73(2):336-342.

38. Mestdag I, Glorieux I. Change and stability in commensality patterns: a comparative analysis of Belgian time-use data from 1966, 1999 and 2004. Sociol Rev. 2009;57(4):703-726.

39. Blake CE, Wethington E, Farrell TJ, Bisogni CA, Devine CM. Behavioral contexts, food-choice coping strategies, and dietary quality of a multiethnic sample of employed parents. J Am Diet Assoc. 2011;111(3):401-407.

40. Bauer KW, Neumark-Sztainer D, Fulkerson JA, Story M. Adolescent girls' weight-related family environments, Minnesota. Prev Chronic Dis. 2011;8(3):A68.

41. Lazarou C, Kalavana T. Urbanization influences dietary habits of Cypriot children: the CYKIDS study. Int J Public Health 2009;54(2):69-77.

42. Roos EB, Karvonen S, Rahkonen O. Lifestyles, social background and eating patterns of 15-year-old boys and girls in Finland. J Youth Stud. 2004;7(3):331-349.

43. Moser A, Chen SE, Jilcott SB, Nayga RM. Associations between maternal employment and time spent in nutrition-related behaviours among German children and mothers. Public Health Nutr. 2012;15(7):1256-1261.

44. Gallegos D, Dziurawiec S, Fozdar F, Abernethie L. Adolescent experiences of 'family meals' in Australia. J Sociol. 2011;47(3):243-260.

45. Devine CM, Farrell TJ, Blake CE, Jastran M, Wethington E, Bisogni CA. Work conditions and the food choice coping strategies of employed parents. J Nutr Educ Behav. 2009;41(5):365-370.

46. Bauer KW, Hearst MO, Escoto K, Berge JM, Neumark-Sztainer D. Parental employment and work-family stress: associations with family food environments. Soc Sci Med. 2012;75(3):496-504.

47. Hsueh J, Yoshikawa H. Working nonstandard schedules and variable shifts in low-income families: associations with parental psychological well-being, family functioning, and child well-being. Dev Psychol. 2007;43(3):620-632.

48. Han WJ, Fox LE. Parental work schedules and children's cognitive trajectories. J Marriage Fam. 2011;73(5):962-980.

49. Prior AL, Limbert C. Adolescents' perceptions and experiences of family meals. J Child Health Care. 2013;17(4):354-365.

50. Eto K, Koch P, Contento IR, Adachi M. Variables of the theory of planned behavior are associated with family meal frequency among adolescents. J Nutr Educ Behav. 2011;43(6):525-530.

51. Neumark-Sztainer D, Wall M, Perry C, Story M. Correlates of fruit and vegetable intake among adolescents. Findings from Project EAT. Prev Med. 2003;37(3):198-208.

52. Neumark-Sztainer D, Story M, Ackard D, Moe J, Perry C. The "family meal": views of adolescents. J Nutr Educ. 2000;32(6):329-334.

53. Berge JM, Hoppmann C, Hanson C, Neumark-Sztainer D. Perspectives about family meals from single-headed and dual-headed households: a qualitative analysis. J Acad Nutr Diet. 2013;113(12):1632-1639.

54. Fulkerson JA, Kubik MY, Rydell S, et al. Focus groups with working parents of school-aged children: what's needed to improve family meals? J Nutr Educ Behav. 2011;43(3):189-193.

55. Brannen J, O'Connell R, Mooney A. Families, meals and synchronicity: eating together in British dual earner families. Community Work Fam. 2013;16(4):417-434

56. Martinasek MP, DeBate RD, Walvoord AG, et al. Using social marketing to understand the family dinner with working mothers. Ecol Food Nutr. 2010;49(6):431-451.

57. Neumark-Sztainer D, Wall M, Fulkerson JA, Larson N. Changes in the frequency of family meals from 1999 to 2010 in the homes of adolescents: trends by sociodemographic characteristics. J Adolesc Health. 2013;52(2):201-206. 
58. Fulkerson JA, Neumark-Sztainer D, Story M, et al. The Healthy Home Offerings via the Mealtime Environment (HOME) Plus study: design and methods. Contemp Clin Trials. 2014;38(1):59-68.

59. Neely E, Walton M, Stephens C. Young people's food practices and social relationships. A thematic synthesis. Appetite. 2014;82: 50-60.

60. Bisogni CA, Jastran M, Seligson M, Thompson A. How people interpret healthy eating: contributions of qualitative research. JNutr Educ Behav. 2012;44(4):282-301.

61. Tiedje K, Wieland ML, Meiers SJ, et al. A focus group study of healthy eating knowledge, practices, and barriers among adult and adolescent immigrants and refugees in the United States. Int J Behav Nutr Phys Act. 2014;11:63.

62. Stang J, Kong A, Story M, Eisenberg ME, Neumark-Sztainer D. Food and weight-related patterns and behaviors of Hmong adolescents. J Am Diet Assoc. 2007;107(6):936-941.
63. Widome R, Neumark-Sztainer D, Hannan PJ, Haines J, Story M. Eating when there is not enough to eat: eating behavior and perceptions of food among food-insecure youths. Am J Public Health. 2009;99(5):822-828.

64. Han W-J, Miller DP. Parental work schedules and adolescent depression. Health Sociol Rev. 2009;18(1):36-49.

65. Barker M, Robinson S, Wilman C, Barker DJP. Behaviour, body composition and diet in adolescent girls. Appetite. 2000;35(2):161-170.

66. Neumark-Sztainer D, Wall M, Story M, van den Berg P. Accurate parental classification of overweight adolescents' weight status: does it matter? Pediatrics. 2008;121(6):e1495-e1502.

67. Berge JM, Wall M, Neumark-Sztainer D, Larson N, Story M. Parenting style and family meals: cross-sectional and 5-year longitudinal associations. J Am Diet Assoc. 2010;110(7):1036-1042.

68. Zaborskis A, Zemaitiene N, Borup I, Kuntsche E, Moreno C. Family joint activities in a cross-national perspective. BMC Public Health. 2007;7:94.

\section{Publish your work in this journal}

Adolescent Health, Medicine and Therapeutics is an international, peer-reviewed, open access journal focusing on health, pathology, and treatment issues specific to the adolescent age group. All aspects of health maintenance, preventative measures and disease treatment interventions are addressed within the journal and practitioners from

\section{Dovepress}

all disciplines are invited to submit their work as well as healthcare researchers and patient support groups.. The manuscript management system is completely online and includes a very quick and fair peerreview system. Visit http://www.dovepress.com/testimonials.php to read real quotes from published authors.

Submit your manuscript here: http://www.dovepress.com/adolescent-health-medicine-and-therapeutics-journal 